\title{
XII. Examination of Mr. Alfred R. Wallace's modification of the physical theory of secular changes of climate
}

\author{
James Croll LL.D. F.R.S.
}

To cite this article: James Croll LL.D. F.R.S. (1884) XII. Examination of Mr. Alfred R. Wallace's modification of the physical theory of secular changes of climate, Philosophical Magazine Series 5, 17:104, 81-111, DOI: 10.1080/14786448408627487

To link to this article: http://dx.doi.org/10.1080/14786448408627487

冓 Published online: 29 Apr 2009.

Submit your article to this journal $₫$

Џll Article views: 2

Q View related articles $₫$ 
LONDON, EDINBURGH, AND DUBLIN

\title{
PHILOSOPHICAL MAGAZINE
}

\author{
AND \\ JOURNAL OF SCIENCE.
}

[FIFTH SERIES.]

$F E B R U A R Y 1884$.

XII. Examination of Mr. Alfred R. Wallace's Modification of the Physical Theory of Secular Changes of Climate. By James Crold, LL.D., F.R.S.*

( $\mathrm{N}$ the publication of 'Island Life,' upwards of three years ago, the author kindly favoured me with a copy. $\mathrm{He}$ at the same time wrote to me stating that the volume contained some modifications of my theory of secular changes of climate, to which he had been led by a careful consideration of the subject, and that he would be glad to have an expression of my opinion in regard to his results. Deeply interested as I, of course, felt in the matter, I was however compelled, owing to the state of my health, to leave the volume unread till within the last few months. This fact will account for the appearance of the following remarks at this somewhat late date.

I have read the chapters relating to Geological Climate with the greatest amount of interest and pleasure, and have to thank the author for his very clear and able exposition and defence of the main points of my theory. It appears to me, however, that what Mr. Wallace regards as modifications are in some cases really necessary parts of the theory. These may not, it is true, have been in all cases expressed by me, but they are nevertheless implied in the theory. Other points, again, regarded as modifications are simply facts lying altogether outside of the theory, which can in no way affect it. With

* Communicated by the Author.

Phil. Mag. S. 5. Vol. 17. No. 104. Feb. 1884. 
much that Mr. Wallace has advanced in explanation of geological climate I fully agree ; but I am, nevertheless, wholly unable to perceive that any of his arguments or considerations do in reality materially affect the theory advocated in 'Climate and 'Time.' This I hopo presently to show.

Before proceeding, however, to examine in detail Mr. Wallace's modifications of the theory, it may be as well to consider one or two minor points on which I differ from him, as this will save the necessity of referring to them when we come to discuss his main argument.

Effect of Winter Solstice in Aphelion.-- At page 126 ("Island Life') he says:--"We may therefore say generally, that during our northern winter, at the time of the glacial epoch, the northern hemisphere was receiving so much less heat from the sun as to lower its surface-temperature on an average about $35^{\circ} \mathrm{F}$., while during the height of summer of the same period it would be receiving so much more heat as would suffice to raise its mean temperature about $60^{\circ} \mathrm{F}$. above what it is now." In a footnote he adds that "the reason of the increase of summer heat being $60^{\circ}$ while the decrease of winter cold is only $35^{\circ}$, is because our summer is now below and our winter above the average."

There is surely a confusion of ideas here. It is of course true that, as our summer at present occurs in aphelion and our winter in perihelion, the temperature of the former is below and that of the latter above the average; but this can afford no grounds for the result Mr. Wallace attributes to it unless it be assumed (for which there are no astronomical grounds) that our summer is $25^{\circ}$ further below the average than our winter is above it.

On the Storage of Cold.-In a section on the Effects of Snow on Climate, Mr. Wallace points out the different effects produced by water falling as a liquid in the form of rain and as a solid in the form of snow. The rain, however much of it may fall, runs off rapidly, he states, without producing any permanent effect on temperature. But if snow falls, it lies where it fell, and becomes compacted into a mass which keeps the earth below and the air above, at or near the freezing-point. When the snow becomes perpetual, as on the summits of high mountains, permanent cold is the result; and however strong the sun's rays may be, the temperature of both the air and the earth cannot possibly rise much above the freezing-point. "This," he says, "is illustrated by the often-quoted fact that at $80^{\circ} \mathrm{N}$. lat. Captain Scoresby had the pitch melted on the one side of his ship by the heat of the sun, while water was freezing on the other side owing to the coldness of the air." 
Doubtless this is perfectly correct; but on page 502 he states that he has pointed out with more precision than has, he believes, hitherto been done, the different effects on climate of water in the liquid and solid states. This is a somewhat doubtful statement; for in chapter iv. 'Climate and 'Time,' in Phil. Mag. March 1870, and in other places, will, I think, be found all that this section contains. In fact the influence of snow and ice as a permanent source of cold is one of the main factors of my theory. The three great factors are (1) the influence of snow and ice, (2) the influence of aqueous vapour, and (3) the influence of ocean-currents. How persistently has it been urged as an objection to my theory that, during the glacial epoch, the great heat of the perihelion summer would more than counterbalance the effect of the aphelion winter. But I have maintained that the summers, notwithstanding the intensity of the sun's rays, instead of being warmer than at present, would in reality be far colder; for this reason, that the temperature of a snow-and-ice covered country can never rise much above the freezing-point. As an example of this I pointed out that, "were it not for ice, the summers of North Greenland would be as warm as those of England (whereas in point of fact they are colder than our winters); and that were India covered with an ice-sheet, its summers would be colder than those of England.'

"Another point," he says, "of great importance in connexion with this subject is the fact, that this permanent storing-up of cold depends entirely on the annual amount of snowfall in proportion to that of the sun- and air-heat, and not on the actual cold of winter, or even on the average cold of the year." This, I have shown (American Journal of Scienco, Oct. 1883 ; Phil. Mag. Oct. 1883) at considerable length, is one of the most widespread and fundamental errors wilhin the whole range of geological climatology. Perpetual snow, instead of being due "entirely" to the annual amount of snowfall in proportion to the quantity of heat received by the snow, is in most cases not even mainly due to this cause. Overlooking the fact that in the conservation of snow the temperature of the snow is one of the main factors has been a fruitful source of error.

High Land and Heavy Snowfall in relation to the Glacial Epoch.-According to Mr. Wallace, "high land and great moisture" are essential to the initiation of a glacial epoch. Undoubtedly high land and great moisture are the most favourable conditions for bringing about a glacial state of things; but I can hardly agree with him that they are necessary and indispensable. 
As to the second of these conditions, great moisture is evidently necessary only in order to produce a great snowfall; a great snowfall is necessary only in order that the snow may become permanent; and the permanent snow in turn is necessary only in order to have permanent glaciation. But it has already been shown* that we frequently have permanent snow with a very light snowfall, even where the direct heat of the sun is excessive, as on the summits of lofty mountains. Greenland, for example, has but a very small snowfall, and yet the snow and ice are perpetual. What is necessary is, that the small amount which falls should not all melt. If this be the case, the ice will accumulate year by year, and a glacial condition will ultimately result.

Suppose that the annual precipitation of snow on a continent is equivalent to only 10 inches of ice, and that at the end of each summer one inch remains unmelted, then, in this case, the ice will continue to accumulate year by year until the quantity annually discharged by the outward motion from the centre of dispersion equals that annually formed. But in the case of a continent, this condition can be attained only when the sheet at the centre becomes of enormous thickness. Whether high land be necessary to a glacial epoch or not, it is evident that a heavy snowfall is not an indispensable condition.

As to the second of these conditions, namely High Land, it must be borne in mind that the question is not, Could the causes which are now in operation bring about a glacial condition of things without high land? but, Could those physical agencies brought into operation during a high state of eccentricity produce a glacial state of things without high land? Mr. Wallace's answer is that they could not. But I am not satisfied with the grounds on which he bases this opinion. A necessary condition to a glacial epoch is, of course, the existence of perpetual snow; for without perpetual snow there could be no permanent land-ice. The question then is, Could not those physical agencies brought into operation during a high state of eccentricity cover lowlands with perpetual snow without the aid of highlands? Mr. Wallace replies, "Perpetual snow nowhere exists on lowlands." Supposing this were true ( $I$ have endeavoured to show it is nott), still it does not follow that perpetual snow may not have existed on lowlands, or that, when the present condition of things changes, it may not yet exist. It is not difficult to conceive how, under

* American Journal of Science, October 1883; Philosophical Magazine, October 1883.

† Philosophical Magazine, November 1883. 
certain conditions, the snow-line may in some places have been brought to the sea-level. In arctic, or even in subarctic regions, an excessively heavy snowfall, followed by piercingly cold winds from the north, during the whole of the summer months, would keep the snow at a low temperature, and certainly prevent it from disappearing. Keep the surface of the snow at or below the freezing-point, and melting will not take place, no matter how intense the sun's rays may be. A strong wind below the freezing-point will cool the surface of the snow more rapidly than the sun can manage to beat it. Another cause which would tend to keep the snow at a low temperature would be that, along with a cold northerly wind, there is usually a great diminution of aqueous vapour, thus allowing the surface of the snow to radiate its heat more freely into stellar space. For were it not for the aqueous vapour in the atmosphere, the snow-line, even at the equator, would descend to the sea-level*.

Perhaps it is owing to the warm southerly winds of the two-midsummer months that Siberia, even with its inconsiderable snowfall, is not at the present day covered with permanent snow and ice. Mr. Wallace mentions that " in Siberia, within and near the Arctic circle, about six feet of snow covers the country all the winter and spring, and is not sensibly diminished by the powerful sun so long as northerly winds keep the air below the freezing-point, and occasional snowstorms occur. But early in June the wind usually changes to southerly, and under its influence the snow all disappears in a few days." But what would be the consequence wero these northerly winds to continue during the whole of June and July? It would probably be that the snow of autumn would begin to fall before that of spring had disappeared. Were this to result, the country would soon become covered with permanent ice. Matters would be still worse if these southerly winds, instead of ceasing, were simply to change from June and July to December and January, for then, in place of producing a melting effect, they would greatly add to the snowfall.

Such a condition of things may never have obtained on the plains of Siberiat; but I have shown in my paper on the Ice of Greenland and the Antaretic regionst that there are certainly good grounds for concluding that during the glacial

* See American Journal of Science for October 1883; Philosophical Magazine for October 1883.

$\uparrow$ Sir Joseph Dalton Hooker suggests to me that the Ice-eliffs of Siberia may, however, be relics of the Glacial Epoch.

f Phil. Mag. for November 1883. 
epoch, and even at a date more recent, permanent ice must have begun to accumulate on lowlands, which could not have been the case had not the ground been previously covered with perpetual snow.

The only Continental Ice on the Globe probably on Lowlands.-The only two continents on the globe covered by permanent ice and snow are Greenland and the Antarctic. But are these continents to be regarded as high lands or as low lands? Mr. Wallace maintains that they are high lands. "It is," he says, "only where there are lofty mountains or elevated plateaus, as in Greenland \&c., that glaciers accompanied by perpetual snow cover the country. The north polar area is free from any accumulation of permanent ice, excepting the high lands of Greenland and Grinnell Land." And in regard to the Antarctic continent he says, "The much greater quantity of ice at the sonth pole is undoubtedly due to the presence of a large extent of high land." Were it not for these extensive highlands and lofty mountains, Greenland and the Antarctic regions, according to Mr. Wallace's theory, would be free from permanent snow and ice. He, however, nowhere, so far as I can find, offers any proof for the conclusion that those regions possess extensive highlands, elevated plateaus, and lofty mountains sufficient to account for these icy mantles. In the paper just referred to (Phil. Mag. November 1883) I have discussed this subject at considerable length, and have arrived at conclusions diametrically the opposite of those adrocated by Mr. Wallace, viz. that Greenland and probably the greater part of the Antarctic regions consist of land probably not much above sea-level, and that the mass of ice under which they are buried must be due to some other cause than elevation of the land.

\section{Mr. Wallace's Modification of the Theory Examined.}

Mr. Wallace's chief, and, I may say, only real modification of my theory is this. I give it in his own words:-

"The alternate phases of precession-causing the winter of each hemisphere to be in aphelion and perihelion each 10,500 yearswonld produce a complete change of climate only where a country was partially snow-clad; while, whenever a large area became almost wholly buried in snow and ice, as was certainly the case with Northern Europe during the glacial epoch, then the glacial conditions would be continued, and perbaps even intensified, when the sun approached nearest to the earth in winter, instead of there being at the time, as $\mathrm{Mr}$. Croll maintains, an almost perpetual spring."-P. 503.

"When geographical conditions and eccentricity combine to 
produce a severe glacial epoch, the changing phases of precession have very little, if any, effect on the character of the climate, as mild or glacial, though it may modify the seasons; but when the eccentricity becomes moderate and the resulting climate less severe, then the changing phases of precession bring about a considerable alteration and even a partial reversal of the climate."-P. 153.

Again,- " It follows that towards the equatorial limits of a glaciated country alternations of climate may occur during a period of high eccentricity, while near the pole, where the whole country is completely ice-clad, no amelioration may take place. Exactly the same thing will occur inversely with mild Arctic climates."P. 154.

I have, on the contrary, maintained that the more severe the glacial condition of the one hemisphere, the warmer and the more equable would necessarily be that of the other; for the very same combination of causes which would tend to cool the one hemisphere would necessarily tend to warm the other. The process to a large extent consists of a transference of heat from the one hemisphere to the other. Consequently the one hemisphere could not be heated without the other being cooled, or the one cooled without the other being heated. The hotter the one, the colder the other, and the colder the one, the hotter the other. It therefore follows that the more severe the glacial conditions, the warmer and more equable must be the interglacial warm periods. But, according to Mr. Wallace, there could be no warm interglacial periods, either in temperate or polar regions, except during the commencement and towards the close of a glacial epoch.

Before, however, proceeding to examine in detail the steps by which he arrives at this modification of my theory, it will be as well that the reader should have a clear and distinct knowledge of what that theory really is, and what it professes to explain. These I shall now briefly state in the most general terms, for misapprehension in regard to the main features of the theory lie at the root of most of the objections which have been urged against it.

General Statement of the Theomy.-1st. It is not professed that the theory will account for the condition of climate during all past geological ages. It treats mainly of the cause of Glacial Epochs; and one of its essential elements is that these epochs consist of alternate changes, to a greater or less extent, of cold and warm periods; or, in other words, that glacial epochs must consist of alternate glacial and interglacial periods. The chief, though not the sole, aim of the theory is to account for geological climate in so far as such epochs are 
concerned. Although it could be satisfactorily shown, for example, and this has certainly not yet been done, that during some past geological age, such as the Miocene, the Eocene, or the Cretaceous, the climate was throughout uniformly warm or subtropical, this would not prove that the theory was wrong, unless it could at the same time be shown that the necessary conditions demanded by the theory did then exist. But instead of this supposed condition of climate during Secondary and Tertiary periods being inconsistent with my theory, the fact is, as we shall see by and by, that this theory affords the only rational explanation of such a state of things which has yet been given.

2nd. The theory is not that a high state of eccentricity will necessarily produce a glacial epoch. No misapprehension has been more widespread or more difficult to remove than this. From the very commencement I have maintained that no amount of eccentricity, however great, could produce a glacial condition of things; that the Glacial Epoch was the result, not of a high state of eccentricity, but of a combination of Physical Agencies, brought into operation by means of this high state ${ }^{*}$. As an example of this misapprehension, how frequently has the present condition of the planet Mars been adduced as evidence against the theory. The eccentricity of Mars's orbit is at present greater than that of the Earth's even when at its superior limit; and its southern winter solstice is not far removed from aphelion. It is therefore maintained that, if my theory of the cause of the glacial epoch be correct, the southern hemisphere of Mars ought to be under a glacial condition, and the northern enjoying a perpetual spring-and this, as is well known, is not the case. Here it is assumed that, according to the theory, eccentricity alone ought to produce a glacial epoch, irrespective of the necessary physical conditions. We know with certainty that those physical conditions which, according to the theory, were the direct cause of the glacial epoch on our globe, cannot possibly exist on the planet Mars $\dagger$. Just take one example : either the properties of water on the planet Mars or the conditions of its atmosphere must be totally different from those of our earth; for were our earth removed to Mars's distance from the sun, our seas would soon become solid ice and we could have neither snow nor rain, ocean-currents, nor any of the necessary conditions for secular change of climate. This is doubtless not the present state of Mars; but the reason of this can only be that the physical and meteorological con-

* For this reason I prefer to term the theory the Physical Theory rather than the Eccentricity Theory, as it has been called by some writers.

+ See 'Olimate and Time,' p. 79. 
ditions of the planet must be wholly different from those of the earth.

When we reflect that a very slight change in the properties of aqueous vapour, or in the condition of our atmosphere, would effectually prevent the possibility of a glacial epoch occurring on our earth, notwithstanding a high state of eccentricity, we need not wonder that the planet Mars is not in a state of glaciation. But the eccentricity of Mars, though high, is still far from its superior limit, and the planet may yet, for any thing which we know to the contrary, pass through a glacial epoch.

3rd. Another prevailing misapprehension is the supposition that the theory does not recognize the necessity for geographical conditions. In reading 'Island Life' one might be apt to suppose that one of the chief points of difference between Mr. Wallace and myself is that he regards geographical distribution of sea and land as an important factor in a theory of geological climate, whereas I entirely ignore this condition. Nothing could be further from the truth than such a supposition. I can boldly affirm that the necessity for geographical conditions is as truly a part of my theory as of Mr. Wallace's modification thereof.

One of the most important agencies, according to my view, is the enormous amount of heat conveyed from equatorial to temperate and polar regions by means of ocean-currents, and the deflection of this heat, during a high state of eccentricity, from the one hemisphere to the other. But all this depends on ocean-currents flowing from equatorial to polar regions; and the existence of these currents in turn depends, to a large extent, on the contour of the continents and the particular distribution of sea and land. Take, as one example, the Gulfstream, a current which played so important a part in the phenomena of the glacial epoch. A very slight change in geographical conditions, such as the opening of communication between the Gulf of Mexico and the Pacific, would have greatly diminished, if not entirely destroyed, that stream. Or, as I showed on a former occasion, a change in the form or contour of the north-east corner of the South-American continent would have deflected the great equatorial current, the feeder of the Gulf-stream, into the Southern Ocean and away from the Carribean Sea. One of the main causes of the extreme condition of things in North-western Europe, as well as in eastern parts of America, during the glacial epoch, was a large withdrawal of the warm waters of the Gulf-stream; and this was to a great extent due, as I stated in my very first paper on the subject*, to the position of Cape St. Koque, * 1.hil. Mag. for August 1864. 
which deflected the equatorial current into the Southern Ocean. That a geographical distribution of land and water permitting of the existence and deflection of those heat-bearing currents is one of the main factors in my theory is what must be obvious to every reader of 'Climate and Time.'

The difference between Mr. Wallace and myself is this:I maintain that with the present distribution of land and water, without calling in the aid of any other geographical conditions than now obtain, those physical agencies detailed in 'Climate and Time' are perfectly sufficient to account for all the phenomena of the glacial epoch, including those intercalated warm periods, during which Greenland would probably be free from ice and the Arctic regions enjoying a mild climate; while Mr. Wallace, on the other hand, maintains that without assuming some change in the geographical conditions of our globe those physical agencies will not account for that state of things, at least in so far as the disappearance of the ice in Arctic regions is concerned.

To narrow the field of inquiry, and bring more prominently before the mind the real question at issue, I shall state the main points on which Mr. Wallace and I appear to agree.

Points of agreement.-1. Mr. Wallace agrees with me that a high state of eccentricity could never directly produce a glacial condition of climate; that the glacial epoch was the direct result, not of a high state of eccentricity, but of a combination of physical agencies brought into operation by means of this high state.

2. He agrees with me also in regard to what these physical agencies really were; for the agencies to which he refers in his 'Island Life' are almost identically those which I have advanced in 'Climate and Time' and elsewhere.

3. Mr. Wallace agrees with me in regard to the mutual reactions of the physical agents. He maintains with me that these physical agencies not only all lead to one result-the accumulation of snow and ice-but that their efficiency in bringing about this result is strengthened by their mutual reactions on one another. At pp. 137-139 he gives a variety of examples of these mutual reactions, and says that they "produce a maximum of effect which, without their aid, would be altogether unattainable."

4. As has already been shown, we both agree as to the necessity of certain geographical conditions for the production of the glacial epoch. For although that epoch was mainly brought about by the physical agencies, yet these agencies could not have produced the required effect unless the necessary geographical conditions had been supplied, these being necessary for their effective operation. 
5. Mr. Wallace admits, of course, that the necessary geographical conditions existed during the glacial epoch; for, unless this had been the case, no glacial epoch could have occurred. Therefore all that was required to produce glaciation was an amount of eccentricity sufficient to set the physical agencies into operation. Be it observed, it did not require, in addition to the physical agencies, some changes in the geographical conditions, or some new conditions; for the geographical conditions being existent, all that was then required to bring about the glacial epoch was the operation of the physical agencies. The overlooking of this fact has led to much confusion. For example, 210,000 years ago, with winter in aphelion, "the problem to be solved," says Mr. Wallace, "is, whether the snow that fell in winter would accumulate to such an extent that it would not be melted in summer, and so go on increasing year by year till it covered the whole of Scotland, Ireland, and Wales, and much of England. Dr. Croll and Dr. Geikie answer without hesitation that it would. Sir Charles Lyell maintained that it would only do so when geographical conditions were favourable" (p. 136). Here we have a complete misapprehension of the relation between Sir Charles Lyell's views and mine; for I would certainly maintain (and, I presume, Dr. Geikie also) as emphatically as Sir Charles could do, "that it would only do so when geographical conditions were favourable." For undoubtedly, according to the theory advocated in 'Climate and Time,' no glacial epoch conld result without geographical conditions suitable for the operation of the physical agencies ; and this is virtually what Sir Charles maintains. The glacial epoch resulted during the last period of high eccentricity because the geographical conditions suitable for the effective operation of the physical causes then existed.

6. It is assumed in 'Climate and Time' that, with the exception of those resulting from oscillations of sea-level, afterwards to be considered, the general distribution of sea and land, and other geographical conditions, were the same during the glacial epoch as they are at present*. Consequently, in accounting for the glacial epoch I had only to consider the

* Prof. J. Geikie, however, believes that during early Postglacial times a considerable change in the physical geography of the North seas took place (see 'Prehistoric Europe,' chap. xxi.). In order to account for the floras of Greenland, Iceland, and the Faröe lslands, he thinks a land connexion must have existed between these places and Scandinavia. For reasons which will be stated on a future occasion I am somewhit doubtful on this point. There is, I think, an important agent overlooked in the question of the distribution of Arctic flora and fauna. Prof. Geilie, however, does not believe that the climatic condition of that period was in any way due to this change. 
effects resulting from those physical agencies called into operation by an increase of eccentricity. To have speculated on hypothetical geographical conditions different from those which now obtain, and on the influence which these may have had in bringing about the glacial epoch, would have been on my part perfectly absurd, as I knew we had no evidence of the existence of any such conditions. Besides, my aim was to account for that epoch from known and established facts and principles without the introduction of hypothetical causes. I fear that the fact of my making little or no allusion to geographical conditions in my explanations may have unfortunately led Mr. Wallace and others to conclude that I altogether ignore, or, at least, undervalue their importance, which is certainly not the case.

Although Mr. Wallace so frequently alludes to the importance of geographical conditions, I am not sure if he believes that during the glacial epoch those conditions differed materially from what they are at present, or that glaciation could have been greatly influenced by any difference which did exist.

7. Mr. Wallace alludes to one or two geographical conditions which, if they had existed during the glacial epoch, would have greatly aided glaciation; as, for example, if a land-barrier had extended from the British Isles, across the Faröe Islands and Iceland to Greenland, cutting off from Northern Europe the warm waters of the Atlantic, including the Gulf-Stream. "The result," he says, "would almost certainly be that snow would accumulate on the high mountains of Scandinavia till they became glaciated to as great an extent as Greenland."

It would be easy to multiply cases of this kind where a distribution of land and water different from the present might have been more favourable to glaciation than the present; but the question is, Did any such difference favouring glaciation actually exist during the glacial epoch? I have never been able to find any evidence that it did. Many a change in geographical conditions has taken place during Tertiary times, some of which were doubtless favourable to glaciation; but have we any evidence that during the glacial epoch the geographical conditions were more favourable than they are at present? Unless this can be shown to be the case, there is no necessity for referring to a difference in geographical conditions during that epoch as a cause of glaciation. This being so, it does not follow, because in my explanation of the cause of the glacial epoch I may not, like Sir Charles Lyell and others, have speculated on the effects which might 
have resulted had the distribution of land and water been different from what it is now, that I ought on this account to be charged with undervaluing the importance of geographical conditions.

Mr. Wallace refers to one case of a difference in geographical conditions which he thinks might have aided glaciation. Prof. Dana has expressed the opinion that, during the height of the glacial epoch, North-eastern America was considerably elevated, bringing the wide area of the banks of Newfoundland far above water. This, Mr. Wallace thinks, would reduce the southward-flowing Arctic currents, causing the icebergs to hang about the American shores, chilling the air so as to produce constant fogs and clouds with almost perpetual snow-showers, even at midsummer. But Prof. Dana has also shown that during the glacial epoch Northeastern America was depressed as well as elevated. Now the point is, whether the elevation was contemporaneous with the cold, or with the warm periods of the glacial epoch? Mr. Wallace himself admits that depression, not elevation, of the land accompanied the increased cold; and he quotes Mr. Searles V. Wood, jun., approvingly as holding the same opinion (p. 115). It was quite natural for Prof. Dana to suppose that the elevation to which he refers occurred at the time the country was buried under ice; for when he wrote he believed the glacial epoch was chiefly due to elevation of the land caused by the lateral pressure resulting from the shrinking of the earth's crust. It is now, however, pretty well established that the continental or elevated periods of the glacial epoch, when our island was united to the mainland, were warm periods; for it was then that this country was invaded by tropical and subtropical mammalia. Had the climate at that time been cold, and the country even partially covered with snow and ice, these animals would not have made their appearance. It is therefore probable that the elevation to which Prof. Dana refers may have taken place during some of those warm periods. But be this as it may, even were it proved that during the glacial epoch geographical conditions were more favourable for the formation of ice than the present, this would not affect the general conclusion at which I wish to arrive.

Trusting that these preliminary considerations may tend to remove the partial confusion in which this somewhat complex subject has been involved, I shall now proceed to examine $\mathrm{Mr}$. Wallace's main argument. I shall consider it, first, in relation to physical principles, and, secondly, in relation to geological and palæontological facts. 


\section{Physics in relation to Mr. Wallace's Modification of the Theory.}

The grand modification, that during the height of the glacial epoch the snow and ice would not disappear when precession brought the winter solstice round to perihelion, I have already given in Mr. Wallace's own words. As the reasons which he assigns for this modification are very briefly stated by him, I may here give them also in his words.

After describing the state of North-eastern America and the North Atlantic, to which I have already alluded, he says :-

"But when such was the state of the North Atlantic (and, however caused, such must have been its state during the height of the glacial epoch), can we suppose that the mere change from the distant sun in winter and near sun in summer, to the reverse, could bring about any important alteration-the physical and geographical causes of glaciation remaining unchanged? For, certainly, the less powerful sun of summer, even though lasting somewhat longer, could not do more than the much more powerful sun did during the phase of summer in perihelion, while during the less severe winters the sun would have far less power than when it was equally near and at a very much greater altitude in summer. It seems to me, therefore, quite certain that whenever extreme glaciation has been brought about by high eccentricity combined with favourable geographical and physical causes (and witbout tbis combination it is doubtful whether extreme glaciation would ever occur), then the ice-sheet will not be removed during the alternate phases of precession, so long as these geographical and physical causes remain unaltered. It is true that the warm and cold oceanic currents, which are the most important agents in increasing or diminishing glaciation, depend for their strength and efficiency upon the comparative extents of the northern and southern ice-sheets ; but these ice-sheets cannot, I believe, increase or diminish to any important extent unless some geographical or physical change first occurs."-P. 150.

Again,- " It is quite evident that during the height of the glacial epoch there was a combination of causes at work which led to a large portion of North-western Europe and Eastern America being buried in ice to a greater extent even than Greenland. Among these causes we must reckon a diminution of the force of the GulfStream, or its being diverted from the north-western coasts of Furope; and what we have to consider is, whether the alteration from a long cold winter and short hot summer, to a short mild winter and long cool summer would greatly affect the amount of ice if the ocean-currents remained the same. The force of these currents is, it is true, by our hypothesis modified by the increase or diminution of the ice in the two hemispheres alternately, and they then react upon climate; but they cannot be thus changed 
till after the ice-accumulation has been considerably affected by other causes."-P. 148.

There are some further reasons assigned, which will be considered as we proceed.

From what has already been shown, it will be seen that the causes which led to the glacial epoch may be classed under three distinct groups :-(1) the astronomical, (2) the physical, and (3) the geographical. This threefold division is distinctly recognized by Mr. Wallace in the above quotations, as well as in all his reasoning on the subject of geological climate.

In the astronomical group the main elements are the two following :-1st. A high state of eccentricity producing, on the hemisphere whose winter solstice happens to be in aphelion, a long and cold winter with a short and hot summer, and on the other hemisphere, whose winter solstice, of course, at the time is in perihelion, a short and mild winter with a long and cool summer: 2nd. Precession, transferring these conditions from the one hemisphere to the other alternately every 10,000 or 12,000 years. The physical elements are, of course, the influence of snow and ice, ocean-currents, aqueous vapour, clouds, fogs, and a host of other things which have already been discussed at length*; while the geographical consist of the particular distribution of land and water, elevations or depressions in the sea-bottom, contour of the sea-coast, and other geographical conditions influencing the flow of ocean-currents.

It is to the influence of physical agencies, however, that the glacial epoch is more directly due. The main function of the astronomical agents is to set and keep the physical agencies in operation, and also to determine the character of their operations. For example, the position of the winter solstice in relation to the aphelion or to the perihelion, during a high state of eccentricity, determines whether the physical agencies will produce on a given hemisphere a glacial or a warm condition of climate; while precession determines which of the two hemispheres shall be the glaciated and which the warm. In one respect we may say that the astronomical causes produce glaciation by means of the physical agencies.

The geographical conditions, however, cannot properly be considered to be causes in the sense in which the astronomical and physical are. They are more properly conditions to the production of a glacial epoch than causes. They cannot be

* 'Climate and Time,' chap. iv.; 'American Journal of Science,' Oct. 1883; Phil. Mag. Oct. 1883. 
said to act in the production of glaciation. They are rather permanent and passive conditions enabling the active causes to produce their required effects. Had the glacial epoch resulted from elevation of the land, as some geologists suppose, then this elevation might properly be said to have been the cause of the glacial epoch; but the glacial epoch was produced by no such means, nor by any change in the physical geography of the globe. A certain geographical condition of things was, of course, requisite in order to the effective operation of the astronomical and physical causes. This condition existed at the time of the glacial epoch; and it is only in this sense that that epoch can be referred to any thing geographical.

It is true that a cause, as Sir William Hamilton states, may be defined as "all that without which the effect would not happen;" but this is far too general an expression of cause for practical purposes. We therefore fix on the particular antecedent or antecedents, through the activity of which the event is mainly brought about, and term them the causes of the event, and the others the necessary conditions.

I cannot help thinking that the way in which geographical conditions are spoken of as causes of the glacial epoch has tended to confusion.

During the glacial epoch there were frequent submergences and elevations of the land, or rather oscillations of sea-level, and these, it is true, would produce a change in the relative extent of sea and land. But whether we suppose it to have been the sea which rose and fell in relation to the land, or the land in relation to the sea, it equally follows that the geographical change resulting therefrom could not possibly have been a cause of the glacial epoch. It is now a well-established fact that submergence accompanied glaciation; the glaciation may have been that which led to the submergence; but it could not possibly have been the submergence which led to the glaciation. An elevation of the land would have favoured glaciation, but submergence would not. Its tendency would rather be in the opposite direction. It is now also established, that during the continental period, or period of elevation, the climate was warm and equable; for it was then, as has been remarked, that this country was invaded by tropical and subtropical animals. Now it is equally plain that the elevation could not have been the cause of the heat. Elevation of the land might produce cold, but it could not have been a cause of the heat. It follows therefore that the geographical change resulting from submergence or elevation of the land cannot be regarded as a cause of the glacial epoch; 
for its effect on climate, if it had any, was in opposition to that of the astronomical and physical agencies. It would prove a hindrance, not a help.

Referring now to Mr. Wallace's argument: When glacial conditions in the North Atlantic attained their maximum development, "can we suppose," he asks, "that the mere change from the distant sun in winter, and near sun in summer to the reverse, could bring about any important alteration - the physical and geographical causes of glaciation remaining unchanged?" Here, to begin with, we have an impossible state of things assumed. It is assumed in this question that it is possible for the winter solstice to pass from aphelion to perihelion, and the physical causes to remain unchanged. It is assumed as possible that the astronomical conditions might be reversed without a reversal of the physical.

When the winter solstice is in aphelion it sets in operation many physical causes, the tendency of which is to produce an accumulation of snow and ice; but when the solsticepoint moves round to the perihelion, the tendency of these causes is reversed, and they then undo what they had previously done-melt the snow and ice which they had just produced. Now, what Mr. Wallace asks is this : When, owing to the winter solstice being in aphelion during a high state of eccentricity, a glacial condition of things is produced, will the fact of the solstice-point being moved round to perihelion remove the glacial condition, if the physical causes remain unchanged in their mode of operation? My reply is, it certainly would not. Here it is assumed that the physical causes are working in opposition to the astronomical; that when the solstice is in perihelion the action of the physical causes, instead of being reversed, as it should be according to theory, still continues to produce and maintain a glacial state of things, the same as it did when the solstice-point was in aphelion ; and he asks, will the astronomical causes in this struggle manage to overpower the physical and produce a melting of the ice? I unhesitatingly reply, no; for the physical causes are far more powerful than the astronomical. The astronomical causes, as we have seen, are perfectly unable to produce a glacial state of things without the aid of the physical. How, then, could we expect that they could remove this glacial state if the physical causes were actually working against them?

In thus setting the physical causes against the astronomical, Mr. Wallace is basing his argument for the nondisappearance of the snow and ice on a state of things which cannot possibly under the circumstances exist. His question, to have conPhil. Mirg. S. 5. Vol. 17. No. 104. Feb. 1884. H 
sistency, should be this :- When glacial conditions were at their height \&c., "can we suppose that the mere change from the distant sun in winter and the near sun in summer, to the reverse, could bring about any important alteration-the geographical causes of glaciation remaining unchanged ?" If the question is put thus, and it is the only form in which it can he put to be consistent with the theory which Mr. Wallace himself advocates, then my reply is, that the change from the distant sun in winter and near sun in summer to the near sun in winter and distant sun in summer, aided by the change in the physical causes which this would necessarily bring about, would certainly be sufficient to cause the snow and ice to disappear without any change in the geographical condition of things. The combined influence of the astronomical and physical causes, when the winter solstice is in perihelion, is perfectly sufficient to undo all that they had previously done when the solstice was in aphelion. When the action of the causes is reversed, the effects will be reversed.

Had the glacial epoch been produced by geographical causes, then it is probable that the ice would not have disappeared till these causes were changed. Had the ice, for example, been simply due to an elevation of the land, as some have argued, then it would not probably have disappeared till the land became lowered. But it was the result of no such cause. It was due, not to an elevation of the land, but to a number of physical causes, brought into operation by a high state of eccentricity. This Mr. Wallace fully admits and maintains. A certain geographical state of things was, of course, necessary to enable the astronomical and physical causes to produce the required effect; and this was really all that geographical conditions had to do in the matter. Let this be observed, however, that the same geographical condition of things which favours the accumulation of ice when the winter solstice is in aphelion, favours its disappearance when the solstice is in perihelion. This is obvious, because the same combination of physical agencies which makes the hemisphere in aphelion cold, makes the one in perihelion warm. The heating of the one is, to a large extent, the result of the cooling of the other. It is the transference of heat by ocean-currents from the hemisphere in aphelion to the one in perihelion which is a main reason why the former is cold and the latier warm. Hence a change in geographical conditions is unnecessary for the disappearance of the ice on the hemisphere with the perihelion winter, whether that hemisphere be the northern or the southern.

The tendency of the combined influence of all the causes- 
astronomical, physical, and geographical-is to cool the one hemisphere and to warm the other, to accumulate the ice on the one and remove it from the other. Consequently the same total combination of causes which will produce an accumulation of ice on either hemisphere when the winter solstice is in aphelion will produce a melting of that ice when the solstice moves round to the perihelion.

Another Impossible Condition assumed.- "What we have to consider," says Mr. Wallace, "is whether the alteration from a long cold winter and short hot summer, to a short mild winter and long cool summer, would greatly affect the amount of ice if the ocean-currents remained the same." Here, again, we have an impossible state of things assumed. It is assumed that, nothwithstanding the change from an aphelion to a perihelion winter, the ocean-currents would still remain the same. And it is asked, would the astronomical causes in this case remove the glaciation? I would be disposed to say that they would not.

"The force of these currents," he adds, "are, it is true, by our hypothesis modified by the increase or diminution of the ice in the two hemispheres alternately (they depend for their strength and efficiency upon the comparative extent of the northern and southern ice-sheets), and they then react upon climate ; but they cannot be thus changed till after the iceaccumulation has been considerably affected by other causes."

What, then, are the other causes which affect the iceaccumulation and thus lead to a change in the ocean-currents? "These ice-sheets cannot, I believe," says Mr. Wallace, "increase or diminish to any important extent unless some geographical or physical change first occurs." The first thing required to affect the ice-accumulation is thus a geographical or a physical change. But we have just seen that the character of the physical causes depends upon the astronomical. A change from a long cold winter and short hot summer to a short mild winter and long cool summer would reverse the operations of the physical causes and lead to a melting of the ice. The physical causes therefore offer no barrier. What more do we still require? This we have in the following footnote at page $150:-$ - The ocean-currents are mainly due to the difference of temperature of the polar and equatorial areas combined with the peculiar form and position of the continents, and some one or more of these factors must be altered before the ocean-currents towards the North Pole can be increased."

One of these factors-change in the form and position of the continents-may be left out of consideration; for we have no H 2 
evidence of any such change during the glacial epoch, except one, which, as has been already proved, could have had no effect. We must therefore look to a change in " the difference of temperature of the polar and equatorial areas "for any increase in the currents towards the north pole. And in order to bring about this change, "the only available factor," Mr. Wallace states, " is the antarctic ice; if this were largely increased, the northward-flowing currents might be so increased as to melt some of the arctic ice. But without some geographical change the antarctic ice could not materially diminish during its winter perihelion, nor increase to any important extent during the opposite phase. We therefore seem to have no available agency by which to get rid of the ice over a glaciated country, so long as the geographical conditions remained unchanged and the eccentricity continued high."

According to $\mathrm{Mr}$. Wallace, the only available factor to produce a difference of temperature between the south-polar area and the equator, so as to increase the north-flowing currents and thus melt the arctic ice, would be an increase of the antaretic ice; but this he considers impossible without some geographical change. Without such a change, the antarctic ice, he maintains, would neither be increased nor diminished. Hence it follows that without this change there is, according to Mr. Wallace's theory, no possibility of getting quit of our northern ice during interglacial periods.

This sweeping conclusion seems to be based on two assumptions, both of which appear to me to be erroneous. First, that the "only" factor available is the antaretic ice; and, secondly, that the antarctic ice can neither be increased nor diminished without some geographical change.

$A$ Geographical Change not necessary in order to remove the Antarctic Ice.-In reference to the first, that the antaretic ice is the "only" available factor, I shall presently show that there are other causes affecting the northward-flowing currents as powerfully as the antarctic ice. As to the second, that the antarctic ice can neither be increased nor diminished materially without some geographical change, this is an assumption based, no doubt, on the opinion which he holds that the antarctic ice is due to the elevated nature of that continent. Of course if this opinion be correct, then, without a lowering of the land, the ice can never disappear or be greatly changed in amount by astronomical or physical causes. But from what has already been stated in a former article * in reference to the condition of the Antarctic regions, I think it likely that

* "The Ice of Greenland"and the Antarctic Continent not due to Elevation of the Land," Phil. Mag. November 1883. 
they probably consist of low dismembered land or of groups of flat islands little elevated above sea-level, but all fused together by one continuous sheet of ice. In fact, it seems highly probable that a very large portion of the ice rests on a surface which is under the sea-level. Victoria Land is, of course, certainly elevated and mountainous, but the character of the Antarctic icebergs shows that this state of things must be the exception and not the rule in those regions.

If this be the case, the antarctic ice is just in the condition admitting of its being easily modified by warm currents from equatorial regions. In fact at the very present day, as Dr. Neumayer has shown, the slight southward deflections of the warm westerly drift-current caused by the projecting landmasses of Australia, Africa, and South America, cut notches in the ice. When the southern winter solstice was in peribelion during the glacial epoch, it is probable that the greater part of the ice then disappeared.

In fact this is a result which would be even still more likely to occur were the views held by Sir Joseph Dalton Hooker and some others as to the nature of the antarctic ice proved to be correct. Sir Joseph thinks that much of the Antaretic ice-sheet, thousands of feet in thickness as it is, was formed by the successive accumulations of snow year by year on packice. The snowfall in the Antarctic regions he believes to be enormous both during summer and winter; and as but a very small portion of it melts, the accumulated snow is perfectly sufficient to form such a sheet. $\mathrm{He}$ does not consider that there is land enough in the south-polar area to supply the astounding number and gigantic size of the icebergs that infest the ocean between lat. $50^{\circ}$ and $70^{\circ}$. If this theory of Sir Joseph's be correct, and immense masses of the ice are really afloat, we can easily understand how the whole might, during a southern interglacial period, be broken up, dispersed, and melted by an inflow of equatorial water.

I think, however, that the whole of that enormous sheet from which the icebergs are derived must be resting on the ground, although it is very likely, as has been shown on a former occasion*, that a very large portion of it may be on the sea-bottom. The weight of evidence seems to favour the assumption that probably the greater part of the Antarctic regions, as has just been stated, consists of low flat groups of islands separated by broad and shallow seas which have all become filled with solid ice. It is quite possible that the ice filling these seas may have originated in pack-ice, which ultimately became converted into a solid and continuous sheet by

* Phil. Mag. November 1883, p. 357 . 
long ages of successive snowfalls. As layer after layer, converted into ice, was being heaped upon it year by year, the mass would gradually sink till it rested on the sea-bottom*. After this it would assume all the characteristics of continental ice. In fact we have a condition of things exactly similar in the North Sea during the height of the glacial epoch (see 'Climate and Time,' p. 449).

If such be the condition of the antarctic ice, we can readily understand how it might all soon disappear under the influence which would be brought to bear upon it were the eccentricity high and the southern winter solstice in perihelion. The warm and equable conditions of climate which would then prevail, and the enormous quantity of intertropical water carried into the Southern Ocean, would soon produce a melting of the ice. Layer after layer would disappear off the surface, and as soon as the weight of the sheet became less than that of the water which it had displaced, the sheet would float. After this it would no doubt shortly break up and become dispersed.

Other Causes than Antarctic Ice affecting the Northwardflowing Currents. - If we consider the effect which the present amount of eccentricity, small as it is, has on the climatic condition of some parts of the southern hemisphere, we shall readily understand how, during the glacial epoch, the warm water of this hemisphere may have been impelled northward, even independently of the influence of the Antarctic ice. In order to show the present effect of eccentricity on climate I cannot do better than quote Mr. Wallace's own words on the subject. Referring to its effects on south temperate Americi, he says:-

"Those persons who still doubt the effect of winter in aphelion with a high degree of ecentricity in producing glaciation, should

* In this opinion I am glad to find that Sir Joseph to a certain extent concurs, for in a letter to me on the subject he says:- "I cannot doubt but that the icebergs have originated from the ice of the great southern barrier; and what I suspect is that much of this barrier-ice originated in pack-ice over very shallow bays, increased by successive snowfalls. The quantity of snow that falls in summer is enormous south of latitude $50^{\circ}-60^{\circ}$. Certainly it fell on half the days of each summer month during the three seasons we spent in those seas, and I think in one month snow feil every day. There is no summer melting of snow and ice in the Antarctic as there is in the Arctic regions. It is the only region known to me where there is perpetual snow on land at sea-level."

Now if the snow which falls in the Antarctic regions at the sea-level does not all melt, but some of it remains year by year, then permanent ice formed at the sea-level, whether it be on frozen pack or on the ground, must be a necessary consequence. If this be so, it cannot be true, as $\mathrm{Mr}$. Wailace affirms, that there is no permanent ice formed but on high land. 
consider how the condition of south temperate America at the present day is explicable if they reject this agency. The line of perpetual snow in the southern Andes is so low as 6000 feet in the same latitude as the Pyrenees; in the latitude of the Swiss Alps, mountains only 6200 feet high produce immense glaciers which descend to the sea-level; while in the latitude of Cumberland, mountains only from 3000 to 4000 feet high bave every valley filled with streams of ice descending to the sea-coast and giving off abundance of huge icebergs. Here we have exactly the condition of things to which England and Western Europe were subjected during the latter portion of the glacial epoch, when every valley in Wales, Cumberland, and Scotland had its glacier; and to what can this state of things be imputed, if not to the fact that there is now a moderate amount of eccentricity and the winter of the southern hemisphere is in aphelion? The mere geographical position of the southern extremity of America does not seem especially favourable to the production of such a state of glaciation. The land narrows from the tropies southwards, and terminates altogether in about the latitude of Edinburgh; the mountains are of moderate height ; while during summer the sun is three millions of miles nearer, and the heat received from it is equivalent to a rise of $20^{\circ} \mathrm{F}$. as compared with the same season in the northern bemisphere."-P. 142.

In a similar glacial condition are the islands of South Georgia, South Shetland, Graham Land, Enderby Land, Sandwich Land. There can be little doubt that the present extension of ice in the Antaretic regions is to a considerable extent due also to the influence of eccentricity.

Let us now glance for a moment at the influence which this state of things has at present on northward-flowing currents. One result is that the south-east trades are stronger than the north-east, and as a consequence blow over on the northern hemisphere ten or fifteen degrees beyond the equator. This has the effect, as has been shown ('Clinate and Time,' chapters v. and xiii., and other places), of impelling the warm surface-water of the southern intertropical regions over on the northern hemisphere. It is possible that the greater strength of the south-east trades may to some extent be due to the preponderance of ocean on the southern hemisphere; but there can be little doubt that it is mainly the effect of eccentricity.

The result of this transference of water from the southerm to the northern hemisphere is that the intertropieal waters of the northern hemisphere are between three and four degrees warmer than those of the southern. Another result which follows, as has also been shown, is that the great equatorial currents are made to lie at some distance to the north of the 
equator; hence when they are impelled against the American and the Asiatic continents, and become deflected northwards and southwards, the larger portion of the water goes to the north, and thus raises the temperature of the northern hemisphere. Now if all this results as a consequence from the present small amount of eccentricity, how much greater must have been the effect during the glacial epoch, when the eccentricity was more than three times its present value and the southern winter also, as now, in aphelion! All those effects which we have just been considering would then have been magnified far more than threefold.

Climatic Conditions of the two Hemispheres the Reverse 10,000 or 12,000 years ago : Argument from.-Ten or twelve thousand years ago, when our northern winter solstice was last in aphelion, the climatic conditions were in all probability the reverse of what they are at present. There appears to be pretty good geological evidence that such was the case. This, under the present small amount of eccentricity, shows not only to what an extent climate is affected by eccentricity, but also (and with this we are at present more particularly concerned) that its tendency is to cool the one hemisphere and warm the other, to accumulate the snow and ice on the one and melt them on the other. And this result, to a large extent, is doubtless brought about by its influence on oceancurrents.

There are good reasons for concluding, as Prof. J. Geikie has fully shown *, that at a very recent date (during the time of the formation of the 40-feet raised beach and the deposition of the Carse-clays) the climate was much colder than it is at present. The seas surrounding our Island appear to have had a lower temperature than they have at present; and our Highland valleys seem to have been occupied by local glaciers $\dagger$.

The Carse-clays of Scotland are best developed in the valleys of the Tay, the Earn, and the Forth. These deposits consist of finely laminated clays and silt. "Now and again," says Prof. J. Geikie, "the deposits consist of tough tenacious brick-clay, which does not differ in appearance from similar brick-clays of glacial age." The clay is usually free from stones, but occasionally blocks of six inches or a foot in

* 'Prehistoric Europe.'

† In a paper "On the Obliquity of the Ecliptic," read before the Geological Society of Glasgow in 1867, I concluded that at the time of the deposition of the Carse-clays the mean winter temperature was probably $10^{\circ}$ or $15^{\circ}$ lower than at present, and the Gulf-stream considerably reduced. See also 'Climate and Time,' pp. 403-410. 
diameter are found in it; and Prof. J. Geikie mentions having seen one four feet in thickness. Stones of this size in a fine laminated clay evidently indicate the presence of floating ice. But, as Prof. J. Geikie remarks, "it is rather the general character of the clays themselves than the presence of erratics which indicates colder climatic conditions. The fine tenacious brick-clays are not like the dark sludge and silt which now gather upon the estuarine bed of the Tay, but resemble and in some cases are identical in character with the laminated clays of true glacial age with Arctic shells." These Carse-clays, as he further remarks, appear in a large measure to be made up of the fine "flour of rock" derived from the grinding action of glaciers which then occupied the Highland valleys, and from which muddy waters escaped in large quantities in summer owing to the melting of the snow and ice. In short, these Carse-clays appear to coincide with the most recent period of local glaciers.

During that period some of the glaciers, as Prof. J. Geikie has shown, appear to have even reached the sea-level. For example, at the mouth of Glen Brora, in Sutherland, there is a well-marked moraine with large blocks resting upon, and apparently of the same age as, the deposits of the raised beach *. Mr. Robert Chambers also observed moraine matter resting upon the 30-feet beach at the opening of Glen Iorsa, in Arran. In many of the Highland sea-lochs, says Prof. J. Geikie, glaciers appear to have come down to the sea and calved their icebergs there. This, he thinks, is probably the reason why the $40-50$-feet beach is not often well seen at the heads of such sea-lochs. The glaciers seem in many cases to have flowed on for some distance into the sea, and thus prevented the formation of a beach and cliff-line.

The greater magnitude and torrential character of the rivers of that period were no doubt due to the melting during summer of great masses of snow and ice. The presence of the large Greenland whale, found frequently in the Carse deposits, would seem to indicate a somewhat colder sea than now surrounds our island. A decrease of temperature of the sea is what would necessarily occur from a slight diminution in the volume of the Gulf-stream, arising from the greater deflection of equatorial water into the southern hemisphere.

Another circumstance deserves notice here, as it seems to indicate that the climatic conditions of the two hemispheres were at the period of the Carse-clays the reverse of what they are at present. During that period the sea stood higher in

* 'Prehistoric Europe,' p. 411. 
relation to the land than it does at the present time. To this circumstance alone no great importance can be attached; but, when we consider in addition that submergence has almost invariably accompanied glaciation, we may regard it as highly probable that the submergence at the period in question was the result of a greater amount of ice on the northern hemisphere and a less amount on the southern, than now. This probability is further increased by the fact that during the growth of the ancient Forest, which immediately underlies the Carse-clays, and indicates a condition of climate even more warm and equable than the present*, the sea stood not only higher in relation to the land than it did during the time of the deposition of the Carse-clays, but somewhat higher than it does at present. The buried Forest doubtless belongs to the period 10,000 or 12,000 years prior to that of the Carse-clays $\dagger$, when the winter solstice was in perihelion; and at this time, owing to a somewhat greater amount of eccentricity than at present, the quantity of ice on the southern hemisphere might be expected to be greater, and that on the northern less, than now.

Thus when the northern winters were last in aphelion there was a rise of sea-level, resulting doubtless from a preponderance of ice on the northern hemisphere; but when the buried Forest flourished, 10,000 or 12,000 years prior, the winters were in perihelion, and there was a fall of sea-level, due in all likelihood to the preponderance of ice on the southern hemisphere. But this is not all: the strata which underlie the buried Forest bear witness to another rise of sea-level.

These changes of climatic conditions and oscillations of sealevel, which took place during the latter part of the Postglacial period, are just what should have taken place on the supposition that they were the result of those astronomical and physical agents which we have been considering. Thus, immediately preceding the Present period we have that of the 25- and 40-feet $\ddagger$ raised beaches and the Carse deposits, which indicate that the climate was then more severe and the sea somewhat colder and standing at a higher level than at present. Now during this Recent period our northern winter

* Those who doubt the equable and warmer character of the climate of the submarine Forest-bed period should study the mass of evidence on this point given in 'Prehistoric Europe.'

$\dagger$ For the probable dates of the Carse-clays and the submarine Forestbeds see Appendix.

I At one time I thought ('Climate and Time,' p. 409) that the 40-feet beach might belong to a period 50,000 years prior to the Carse-clays; but I am now satisfied that the two beaches both belong to the period of the Carse-clays, as Prof. J. Geikie has shown. 
solstice was in aphelion, and the condition of things is exactly what, according to theory, we ought to expect.

Preceding the period of the Carse-clays comes that of the buried Forest, when the climate was even more genial and equable than at the present day, the Gulf-stream larger and the sea at a lower level than now. Now during this period the winter solstice was in perihelion and the eccentricity somewhat greater than at present; and here again we have exactly that condition of things which, according to theory, we ought to expect. It would be very singular indeed were there no physical connexion between these conditions and the causes to which I have been attributing them. It would certainly be singular were all these coincidences purely accidental. These changes have all been so recent, geologically speaking, and so general and widespread in their character, that they cannot reasonably be attributed to any known geographical changes. If we admit, then, that they were the result of those astronomical and physical agents to which I have referred them, we must also admit that those agents were as efficient in producing a warm and equable climate as in producing a cold and severe one. We must further admit that, with a very small amount of eccentricity, wide ${ }^{\top} y$ marked differences of climatic conditions are brought about on the two hemispheres; that, when the winters are in perihelion, the melting of the snow and ice and the increase of the Gulf-stream and other northward-flowing currents are as necessary a result as were the formation of the snow and ice and the decrease of the Gulf-stream and those currents when the winters were in aphelion. And if this holds true in reference to recent and postglacial times, when the eccentricity was small, it must, for reasons which will presently be stated, hold true in a higher degree in reference to the glacial epoch, when the eccentricity was more than three times its present value.

The Mutual Reaction of the Physical Agents in relation to the Melting of the Ice.-When the winter solstice is in aphelion it sets in operation, according to theory, as has been shown, a host of physical causes the tendency of which is to produce an accumulation of snow and ice; but when the solstice-point moves round to perihelion the tendency of these causes is reversed, and thoy then undo what they had previously donethey melt the snow and ice which they had just produced. The action of the causes being reversed, the effects are reversed. But it must be observed that the greater the amount of the eccentricitr, the greater will be the effect resulting from the combination of these physical agents, whether that effect be 
the production of snow and ice on the cold hemisphere, or the melting of them on the warm,- -whether it be their production when the winter solstice of a hemisphere is in aphelion, or their melting when that solstice is in perihelion.

We have, however, to take into account not merely the action of the physical agents, but their Mutual Reactions on one another. The effect of this mutual reaction is very striking. Not only do the physical agents, in their actions, all lead to one result, viz. an accumulation of snow and ice when the winters are in aphelion, but their efficiency in bringing about this result is actually strengthened by their mutual reactions on one another. To illustrate this effect I quote the following from a former article:-

"To begin with, we have a high state of eccentricity. This leads to long and cold winters. The cold leads to snow, and although heat is given out in the formation of the snow, yet the final result is that the snow intensifies the cold : it cools the air and leads to still more snow. The cold and snow bring a third agent into play-fogs, which act still in the same direction. The fogs intercept the sun's rays, this interception of the rays diminishes the melting-power of the sun, and so increases the accumulation. As the snow and ice continue to accumulate, more and more of the rays are cut off; and on the other hand, as the rays continue to be cut off, the rate of accumulation increases, because the quantity of snow and ice melted becomes thus annually less and less. In addition, the loss of the rays cut off by the fogs lowers the temperature of the air and leads to more snow being formed, while again the snow thus formed chills the air still more and increases the fogs. Again, during the winters of a glacial epoch, the earth would be radiating its heat into space. Had this loss of heat simply lowered the temperature, the lowering of the temperature would have tended to diminish the rate of loss ; but the result is the formation of snow rather than the lowering of the temperature.

"Further, as snow and ice accumulate on the one hemisphere they diminish on the other. This increases the strength of the trade-winds on the cold hemisphere and weakens those on the warm. The effect of this is to impel the warm water of the tropics more to the warm hemisphere than to the cold. Supposing the northern hemisphere to be the cold one, then, as the snow and ice begin gradually to accumulate, the oceancurrents of that hemisphere, more particularly the Gulf-Stream, begin to decrease in volume, while those on the southern or warm hemisphere begin pari passu to increase. This withdrawal of heat from the northern hemisphere favours the 
accumulation of snow and ice, and as the snow and ice accumulate the ocean-currents decrease. On the other hand, as the ocean-currents diminish, the snow and ice still more accumulate. Thus the two effects, in so far as the accumulation of snow and ice is concerned, mutually strengthen each other."

With all this Mr. Wallace seems fully to agree; for at pp. 137-140 ('Island Life') he gives a very clear statement of the effect of these mutual reactions in the production of glaciation, and says that were it not for them it is probable the astronomical and other causes would not in our latitudes have been sufficient to produce glaciation. In short, he concludes that these reactions "produce a maximum of effect which, without their aid, would be altogether unattainable." Mr. Wallace thus does full justice to these mutual reactions in so far as the production of glaciation is concerned; but I am convinced that he must have underestimated their importance as regards the removal of the glaciation. He, however, recognizes the fact that these mutual reactions produce an opposite effect on the warm atmosphere whose winters are in perihelion. "These agencies," he says, "are at the same time acting in a reverse way in the southern hemisphere, diminishing the supply of the moisture carried by the anti-trades, and increasing the temperature by means of more powerful southward ocean-currents; and all this again reacts on the northern hemisphere, increasing yet further the supply of moisture by the more powerful south-westerly winds, while still further lowering the temperature by the southward diversion of the Gulf-Stream."

Now if, during the glaciation of the northern hemisphere, these mutual reactions produce the opposite effect on the southern hemisphere, it is evident that they must produce this same opposite effect on the northern hemisphere when its winter solstice is in perihelion. Their effect then would be to increase the temperature and melt the ice. When the winter solstice is moving towards the aphelion, the physical agents begin to act and also to react on one another, and this action and reaction go on increasing in intensity till the solsticepoint reaches the aphelion; but an exactly similar thing is going on in the other hemisphere, only the effects are the reverse. While the actions and reactions leading to an accumulation of ice are increasing in intensity, we shall suppose, on the northern hemisphere, the same increase is taking place on the southern hemisphere; but the result is a melting, not an accumulation of the ice. The same process is undoing on the southern hemisphere what it is doing on the northern. Similarly, of course, when the northern winter solstice begins 


\section{On the Physical Theory of Secular Changes of Climate.}

to move towards the peribelion, the mutual reactions of these physical causes will be reversed and will go on with increasing intensity till the peribelion is reached, melting the very ice which they had previously produced.

We have already seen that the greater the extent of the eccentricity, the greater is the effect resulting from the actions of the physical causes, whether this effect be the production of ice on the cold hemisphere, or its removal from the warm. It is evident that the same thing must necessarily hold true in regard to the mutual reactions of the physical causes. Consequently if the mutual actions and reactions of the physical causes, brought into operation during a high state of eccentricity, led at the glacial epoch to the great accumulation of ice when the winters were in aphelion, they must have led to an equally great melting and dispersal of that ice when precession brought the winters round to perihelion. These causes would be as efficient in the removal of the ice as they were in its production. In so far as the physical and astronomical causes were concerned, the greater the amount of ice formed during the cold periods the greater would be the amount melted during the warm interglacial periods.

Another Reason assigned why the Ice does not Melt.-Mr. Wallace assigns the following as an additional reason why the ice does not disappear during the interglacial periods when the eccentricity is high:-

"When a country is largely covered with ice, we may look upon it as possessing the accumulated or stored-up cold of a long series of preceding winters ; and however much heat is poured upon it, its temperature cannot be raised above the freezing-point till that store of cold is got rid of-that is, till the ice is all melted. But the ice itself, when extensive, tends to its own preservation, even under the influence of heat; for the chilled atmosphere becomes filled with fog, and this keeps off the sun-heat, and then snow falls even during summer, and the stored-up cold does not diminish during the year. When, however, only a small portion of the surface is covered with ice, the exposed earth becomes heated by the hot sun, this warms the air, and the warm air melts the adjacent ice. It follows that, towards the equatorial limits of a glaciated country alternations of climate may occur during a period of high eccentricity, while nearer the pole, where the whole country is completely ice-clad, no amelioration may take place."-P. 154.

For the past nineteen years I have been maintaining that, when a country is covered with ice, it becomes a permanent source of cold; and however much heat may be received from 
the sun, the temperature of the surface can never be raised above the freezing-point while the ice remains; and, again, that such an ice-covering tends to its own preservation, because it chills the air and increases the snowfall. In short, I have all along maintained this to have been one of the chief causes which led to the country being so deeply covered with ice. In fact, had it not been for some such conservative power in the ice, a glacial epoch resulting from the causes which I have been advocating would not have been possible. This conservative tendency certainly renders it more difficult for the physical agencies to get rid of the ice during interglacial periods; but we evidently have no grounds for assuming that it will defy their melting-powers.

I shall next consider Geological and Palæontological Facts in relation to $\mathrm{Mr}$. Wallace's modification, and also his theory as to the cause of Mild Arctic Climates.

[To be continued.]

XIII. On a Method of determining experimextally the Constant of an Electro-dynamometer. By A. Р. Снаттоск*.

THE practical importanice attaching to the accurate measurement of electric currents is daily increasing with the extended use of electricity. For this reason I venture to hope that the following account of some experiments on the calibration of an electro-dynamometer will prove interesting.

The twisting moment with which the fixed coil of an electrodynamometer acts on the suspended coil is proportional to the product of the strengths of current flowing through the two coils respectively, and to a factor which depends on their geometrical relations.

If a current be sent through the fixed coil and the suspended coil be allowed to rotate, an E.M.F. is set up in the latter which is at any instant proportional to the speed of rotation, to the strength of the current in the fixed coil, and to a factor depending on the geometrical relations of the two coils.

By allowing the suspended coil to rotate about its axis of suspension, and by making the geometrical factor during rotation the same as afterwards, when the coil is suspended in its place, I have determined the constant of the instrument upon the table.

It is the method I employed in doing this which I have the honour of bringing before you to-day. The diagram shows the arrangement of the apparatus.

* Communicated by the Physical Society, having been read November $24,1883$. 